Original Article

Amit Pradhanang, MS

Neurosurgical Unit, Department of Surgery, TU Teaching Hospital, Kathmandu, Nepal

Mohan R Sharma, MS

Neurosurgical Unit, Department of Surgery, TU Teaching Hospital, Kathmandu, Nepal

Gopal Sedain, MS, MCh

Neurosurgical Unit, Department of Surgery, TU Teaching Hospital, Kathmandu, Nepal

Sushil K Shilpakar, MS

Neurosurgical Unit, Department of Surgery, TU Teaching Hospital, Kathmandu, Nepal

Address for Correspondence:

Mohan R Sharma, MS

Neurosurgical Unit, Department of Surgery, TU Teaching Hospital, Kathmandu, Nepal

Email: mohanrajsharma@gmail.com

Received, 9 August, 2015

Accepted, 19 August, 2015
Nepal Journal of Neuroscience 12:67-71, 2015

\section{External Ventricular Drainage Infections: Experience From a Tertiary Care Center in Nepal}

External Ventricular Drainage (EVD) related infection is one of the most dreaded infections in neurosurgical practice. The primary aim of this study was to assess the incidence of EVD infections in our hospital. In addition, we have made an attempt to evaluate the indication for EVD placement, influence of total drainage time in the risk of catheter infection, the most common bacterial spectra in cerebrospinal fluid (CSF) culture, and their antibiotic sensitivity pattern. This is a retrospective study of all patients who underwent EVD placement over a period of two years.

Out of 60 patients who underwent EVD placement, 52 met the inclusion criteria for analysis. The ventricular catheters were in place from 1 to 23 days. Overall shunt infection rate was $36.5 \%$. CSF cell count significantly correlated with the occurrence of a positive CSF culture (unpaired t test, $\mathrm{p}<0.05$ ). The most common bacterial species isolated were Acinetobacter baumannii and Burkholderia cepacia.

Despite many advances in care, there is still a significantly high incidence of EVD related infections. Contrary to earlier reports, the most common bacterial grown in our center were quite different and their antibiotic sensitivity varied accordingly.

Keywords: CSF, EVD, infection
$\mathrm{E}$ xternalventriculardrainage(EVD)is one of themost commonly performed procedures in neurosurgical practice. Common indications include acute hydrocephalus due to intraventricular hemorrhage (IVH), meningitis and tumors with obstructive hydrocephalus as well as in patients with chronic hydrocephalus that are not fit for a procedure under general anesthesia. It is also used to monitor intracranial pressure in acute traumatic brain injuries, subarachnoid hemorrhages and strokes.

The most dreaded complication arising from EVD placement include infection, with resultant ventriculitis, meningitis, brain abscess, or subdural empyema. Other complications include hemorrhage, misplacement, dislodgement, and blockage. EVD related infections significantly prolong hospital stay, increase costs and often negatively affect the overall prognosis. Reported rates of EVD related infections range from $<5 \%$ up to $23 \%$, most literature quoting close to $10 \%{ }^{1,7}$ An increased risk of infection has been observed in patients with i) subarachnoid or IVH or with concurrent systemic infections, ii) longer duration of catheterization, iii) cerebrospinal fluid (CSF) leakage, iv) frequent manipulation of the EVD system. ${ }^{1,6,8}$

The objectives of the present study is to assess the incidence of EVD infection rate in the study center, identify the most common bacteria retrieved from cultures and the antibiotic sensitivity patterns and estimate the total drainage time related to the risk of a positive bacteriological CSF culture. In addition relevant literature was reviewed elaborately. 


\section{Pradhanang et al}

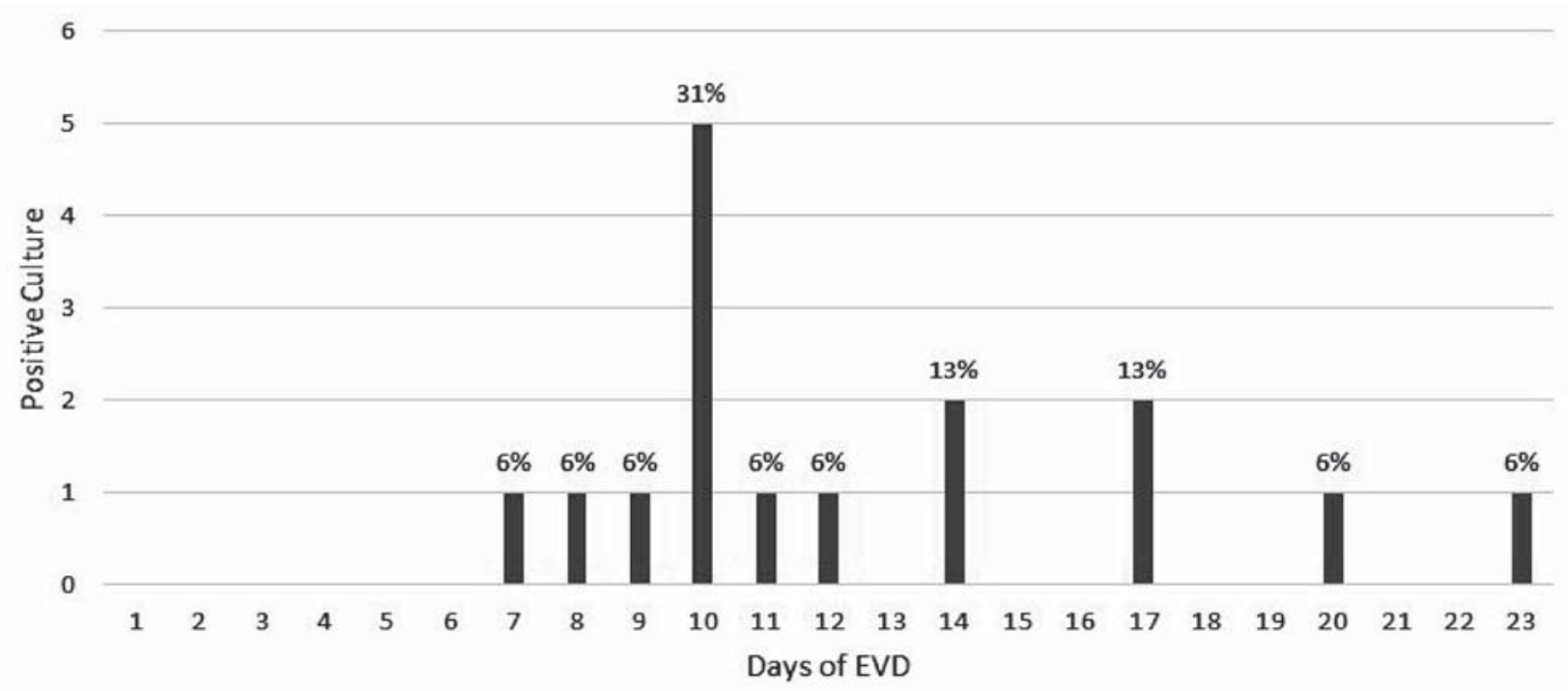

Figure 1: Positivity of bacterial growth in relation to duration of EVD placement $(n=19)$.

\section{Material and Methods}

All patients that underwent EVD placement during a 48 months period (April 2013 to April 2015) at Neurosurgical Unit, Department of Surgery, Tribhuvan University Teaching Hospital, Kathmandu, Nepal were included for analysis. The procedures were all performed in a standard fashion, in the operating theaters under aseptic precautions by neurosurgical residents. All patients received antibiotic therapy, a third generation cephalosporin Ceftriaxone at a dose of $30 \mathrm{mg} / \mathrm{kg}$, at the time of catheter placement. For drainage, conventional (non-medicated) catheters were used. Antibiotic was continued in all patients from the day of insertion until a change was required as shown by culture and sensitivity results to the day of removal. CSF samples were obtained every alternate day from the ventricular drain and examined for cell count, total protein concentration and glucose concentration. Bacteriological CSF cultures were sent twice a week. CSF pleocytosis was defined as a white cell count above $50 / \mathrm{mm}^{3,10}$ A total of 60 patients were evaluated for the study. The charts of all patients were retrospectively reviewed in detail. In addition, demographics and EVD-related data were documented.

Inclusion and Exclusion Criteria: All patients meeting the criteria for EVD placement were included in the study. Those patients who had a preexisting or ongoing CSF infection prior to EVD insertion were excluded.

Definition of Infection: EVD related infection have been variously described as either (i) positive CSF culture result plus clinical symptoms or CNS pleocytosis/ cell count increase, or (ii) in the case of negative CSF culture, clinical symptoms, and CNS pleocytosis/ cell count increase. ${ }^{13,14}$ However in our study we have only labeled those patients who had a positive CSF culture along with clinical symptoms i.e. we have only taken into consideration the first criterion in defining EVD-related infection.

Statistical Analysis: Categorical data were presented as frequencies and percentages and compared using the 2-Tailed t test. All analysis was performed using IBM SPSS Statistics version 21.

\section{Results}

Altogether 60 patients underwent EVD placement during the period of two years. Eight patients already had positive bacteriological growth at the time of EVD placement and were excluded. Only the remaining 52 patients were included in this study. Age ranged from 3 months to 71 years (mean=37.3, SD 26.29). Male to female ratio was equally distributed (30:30). Their diagnoses are summarized in Table 1 below. On analyzing, 19 patients out of 52 grew bacteria in CSF cultures, which meant a significantly high catheter infection rate of $36.5 \%$.

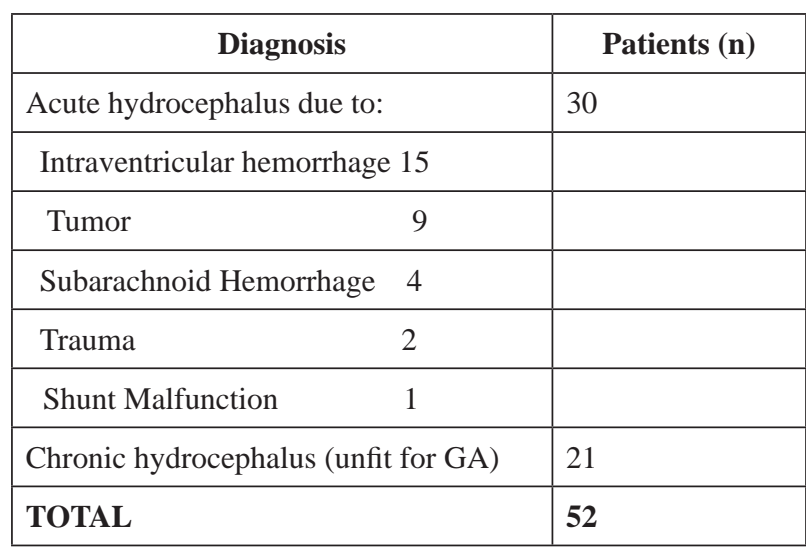

Table 1: Clinical diagnosis of patients requiring EVD $(n=52) . E V D=$ external ventricular drainage. 
EVD Infection

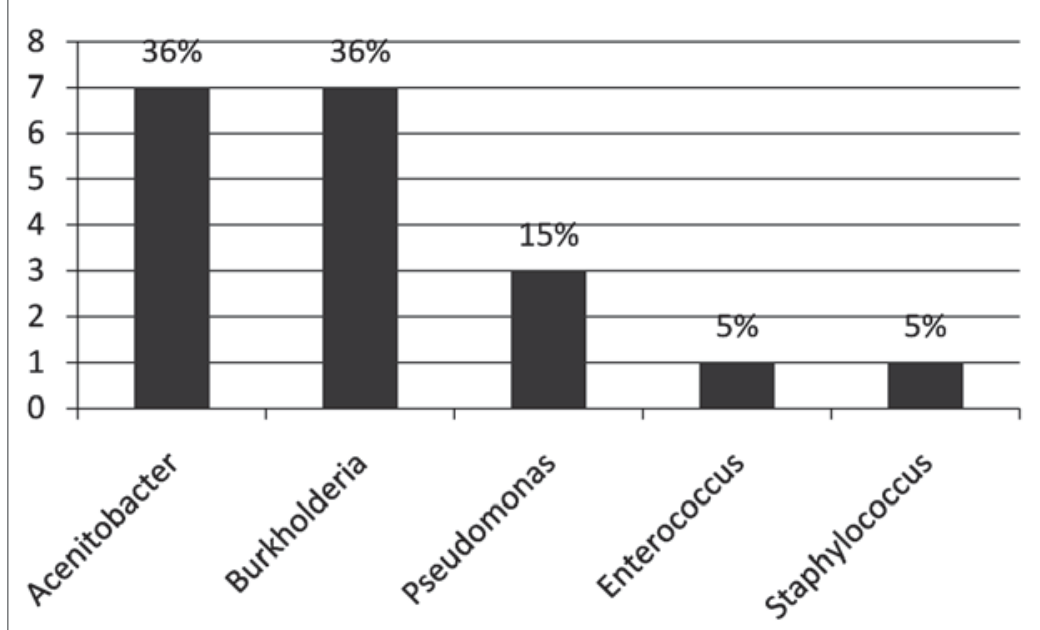

Figure 2: Distribution of bacteria isolated by CSF Analysis ( $n=19)$.

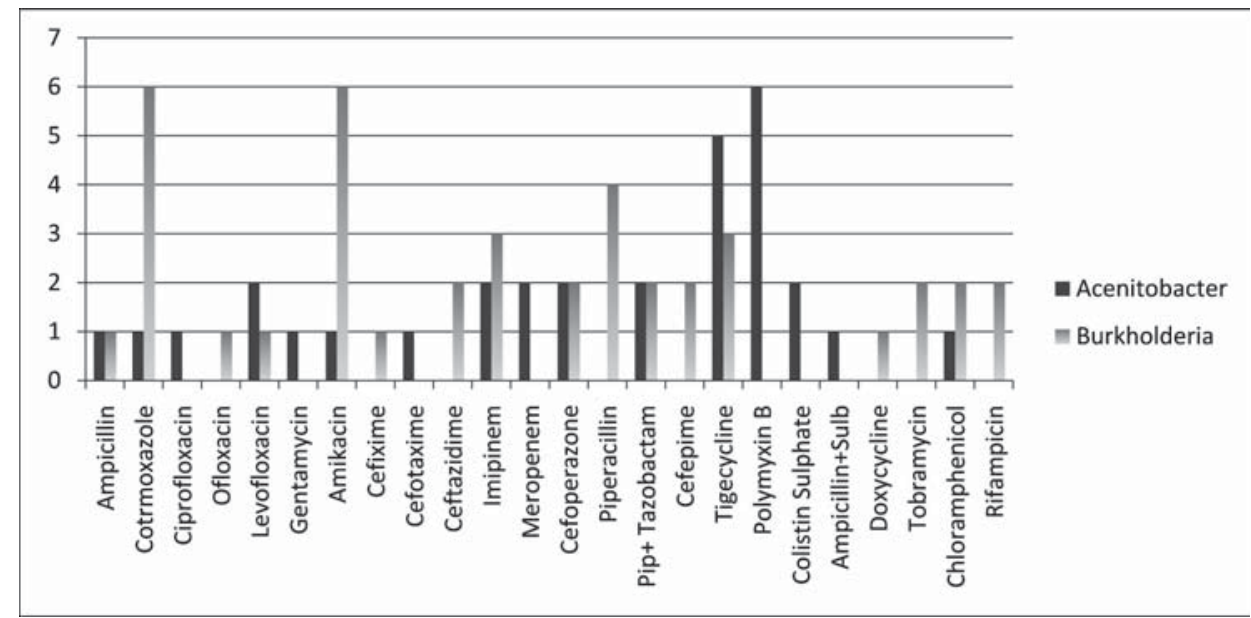

Figure 3: Antibiotic sensitivity pattern of the two most common bacteria species isolated $(n=14)$.

The most common indication for EVD placement was chronic hydrocephalus due to tuberculous meningitis, which was rendered unfit for a definitive neurosurgical procedure for CSF diversion under general anesthesia. Otherwise, these cases would have usually undergone standard ventriculo-peritoneal shunt (VPS) placement.

As shown in (Figure 1), bacteriological growth began from day 7 and was most common at day 10 of EVD placement. However the frequency showed a decreasing trend after day 10 with few spikes on day 14 and 17.

As depicted in (Figure 2), the most common bacteria species isolated from CSF were Acinetobacter $(\mathrm{n}=7)$ and Burkholderia ( $n=7)$.

Among the most common species of bacteria isolated, Acinetobacter was frequently sensitive to Cotrimoxazole and Amikacin while Burkholderia was often sensitive to Tigecycline and Polymyxin B (Figure 3).

We further analyzed the correlation between CSF cell count and culture positivity (Table 2). Those patients with abnormal cell count in CSF analysis were 61 times more likely to have positive bacterial growth compared to those who have normal cell count $(\mathrm{OR}=61.62$, CI: 10.12372.76), $(\mathrm{p}<0.01)$.

\section{Discussions}

Catheter related infections are one of the most common complications in patients with an EVD. Once established, it necessitates aggressive treatment which includes intravenous and often intrathecal administration of potent antibiotics, removal or replacement of ventricular catheter in addition to other supportive measures. Despite these measures, many patients need long term critical care, but still have increased morbidity and mortality. The health care cost in such patients often escalates, which is of major relevance in a country like Nepal with limited resources. Therefore, prevention of catheter infection and its early diagnosis in these patients are of paramount importance. 


\begin{tabular}{|c|c|c|c|c|c|}
\hline & & \multicolumn{2}{|c|}{ Bacterial growth } & \multirow{2}{*}{ p-value } & \multirow{2}{*}{ OR $(95 \% \mathrm{CI})$} \\
\hline & & Yes & No & & \\
\hline & $>50 / \mathrm{mm}^{3}$ & $17(89.5 \%)$ & $4(12.1 \%)$ & $<0.001^{*}$ & $61.62(10.12-372.76)$ \\
\hline Total Count & $<50 / \mathrm{mm}^{3}$ & $2(10.5 \%)$ & $29(87.9 \%)$ & & Ref \\
\hline
\end{tabular}

\section{* Two-tailed t test}

Table 2: Correlation between CSF Pleocytosis and bacterial growth.

Diagnosing EVD related infections on the basis of clinical features is sometimes notoriously difficult, especially in ventilated and ICU patients. Furthermore, patients with intracranial hemorrhage or severe head injury frequently show signs of aseptic meningitis such as headache, nausea, and neck stiffness. High fever with neurological deficits and an elevated leukocyte count in the CSF favor an infection. ${ }^{10}$ In most cases with an external ventricular drainage the diagnosis of CSF infection is based on laboratory findings. In our study, the CSF cell count of the samples with positive bacteriological cultures were analyzed the same day. Those patients with CSF cell counts $>50$ cells $/ \mathrm{mm}^{3}$ were 61 times more likely to have positive bacterial growth compared to those who have CSF cell counts $<50$ cells $/ \mathrm{mm}^{3}$ (OR=61.62, CI: 10.12-372.76), ( $p<0.01$ ). The CSF cell count is a cheap, relatively easy and predictable investigation to diagnose an ongoing infection in a patient with EVD related infections.

The issue of whether or not to give prophylactic antibiotics in patients with EVDs is still controversial. . $^{8,15,17}$ All patients in our study received antibiotics at the time of insertion of their ventricular catheters. Yet, a positive CSF culture was found in an alarming 36.5\% of patients as compared to $10 \%$ in the literature. The possible factors could be related to poor nutritional status, immunosuppression due to tumor or post radiation status, and lack of stringent protocol for catheter placement. Different measures have been advocated to decrease infection rate like the use of antimicrobial impregnated shunts, routine change of catheters or the strict adherence to EVD bundle protocol while insertion of EVD. ${ }^{3,18}$ This high incidence of CSF infections outlines the need for strict aseptic dressing and CSF collection techniques, prompt diagnosis to permit immediate specific treatment, such as the intraventricular administration of antibiotics, or the change of the ventricular catheter in severe infections.,11

The most commonly isolated bacteria in the CSF samples in our study were Acinetobacter baumanni and Burkholderia cepacia species. The causative bacteria were isolated more than once with identical resistance pattern and biotype. Stenager et al in 1986, found Staphyloccous epidermidis as the predominant bacterial growth in EVD samples. ${ }^{15}$ In the study by Camacho et al. in 2011, Acenitobacter contributed to majority (27.3\%) of the infections of which $50 \%$ were carbapenem-resistant. ${ }^{1}$ Pfisterer in 2003, noted majority of infections were caused by Staphylococcus epidermidis. ${ }^{10}$ Rath et al in 2014, noted oagulase negative Staphylococci accounting for majority (62\%) of the infections. ${ }^{11}$ Similarly, Hagel et al in 2014 found the majority of infections caused by coagulasenegative Staphylococcus. ${ }^{4}$ In a meta analysis conducted by Ramanan et al. in 2014 including 35 studies, majority of infections were caused by gram positive bacteria, predominantly by coagulase-negative staphylococci (39\%, including S. epidermidis) and S. aureus (15\%). ${ }^{10}$

In our study, Acinetobacter baumanni was most commonly sensitive to Tigicycline and Polymixin B and resistant to carbapenems and other beta-lactam antibiotics, while Burkholderia cepacia was commonly sensitive to Cotrimoxazole and Amikacin.

Current recommendations from the Infectious Diseases Society of America (IDSA) regarding empirical antimicrobial therapy for postneurosurgical meningitis is intravenous Vancomycin plus either Cefepime, Ceftazidime, or Meropenem. ${ }^{16}$ However multidrug resistant Acinetobacter meningitis is becoming an increasingly common entity especially in neurosurgical patients, claiming mortality exceeding $15 \%$ and necessitating intravenous Polymixin B or Colistin and an intraventricular aminoglycoside. ${ }^{5}$

Limitations of the study: One major limitation of the study is that we analyzed only the CSF samples which grew bacteria in them. Many patients could still have EVD related infections despite a negative bacteriological growth. This could further increase the actual incidence of EVD related infections. On the other hand, we had to exclude significant number of cases with positive initial CSF analysis. This could have skewed the patient distribution. Moreover it was a single center retrospective study. 


\section{Conclusions}

EVD related infections are potentially preventable causes of morbidity and mortality in neurosurgical patients, the incidence of which is quite high. Further multicenter prospective studies are recommended to analyze the true scenario of EVD-related infections.

Acknowledgments: Special thanks to the Department of Microbiology, Tribhuvan University Teaching Hospital, Kathmandu, Nepal.

Conflict of Interest: The authors declare no conflict of interest.

\section{References}

1. Camacho EF, Boszczowski I, Basso M, Jeng BC, Freire MP, Guimarães Tet al. Infection rate and risk factors associated with infections related to external ventricular drain. Infection. 39:47-51, 2011

2. Chatzi M, Karvouniaris M, Makris D, Tsimitrea E, Gatos C, Tasiou A et al. Bundle of measures for external cerebral ventricular drainage-associated ventriculitis. Crit Care Med. 42(1):66-73, 2014

3. Gerner-Smidt P, Stenager E, Kock-Jensen C. Treatment of ventriculostomy-related infections. Acta Neurochir. 91:47-49, 1988

4. Hagel S, Bruns T, Pletz MW, Engel C, Kalff R, Ewald C. External ventricular drain infections: risk factors and outcome. Interdiscip Perspect Infect Dis. 2014:708531, 2014

5. Kim BN, Peleg AY, Lodise TP, Lipman J, Li J, Nation $\mathrm{R}$ et al. Management of meningitis due to antibiotic-resistant Acinetobacter species. Lancet Infect Dis. 9(4):245-255, 2009

6. Kim JH, Desai NS, Ricci J, Stieg PE, Rosengart AJ, Härtl R et al. Factors contributing to ventriculostomy infection. World Neurosurg. 77(1):135-140, 2012

7. Lozier AP1, Sciacca RR, Romagnoli MF, Connolly ES Jr. Ventriculostomy- related infections: a critical review of the literature. Neurosurgery. 51(1):170182, 002

8. Mayhall CG, Archer NH, Lamb VA, Spadora AC, Baggett JW, Ward JD et al. Ventriculostomy-related infections. A prospective epidemiologic study. $\mathbf{N}$
EVD Infection

Engl J Med. 310(9):553-559, 1984

9. Pfisterer W, Mühlbauer M, Czech T, Reinprecht A. Early diagnosis of external ventricular drainage infection: results of a prospective study. J Neurol Neurosurg Psychiatry. 74(7):929-932, 2003

10. Ramanan M, Lipman J, Shorr A, Shankar A. A metaanalysis of ventriculostomy-associated cerebrospinal fluid infections. BMC Infect Dis. 15:3 doi: 10.1186/ s12879-014-0712-z, 2015

11. Rath PM, Schoch B, Adamzik M, Steinmann E, Buer J, Steinmann J. Value of multiplex PCR using cerebrospinal fluid for the diagnosis of ventriculostomy-related meningitis in neurosurgery patients. Infection. 42(4):621-627, 2014

12. Ross D, Rosegay H, Pons V. Differentiation of aseptic and bacterial meningitis in postoperative neurosurgical patients. J Neurosurg. 69(5):669-674, 1988

13. Scheithauer S, Bürgel U, Ryang YM, Haase G, Schiefer J, Koch S et al. Prospective surveillance of drain associated meningitis/ventriculitis in a neurosurgery and neurological intensive care unit. $\mathbf{J}$ Neurol Neurosurg Psychiatry. 80(12):1381-1385, 2009

14. Schultz M, Moore K, Foote A. Bacterial ventriculitis and duration of ventriculostomy catheter insertion. $\mathbf{J}$ Neurosci Nurs. 25:158-164,1993

15. Stenager E, Gerner-Smidt P, Kock-Jensen C. Ventriculostomy-related infections-an epidemiological study. Acta Neurochir. 83(1-2):2023, 1986

16. Tunkel AR, Hartman BJ, Kaplan SL, Kaufman BA, Roos KL, Scheld WM et al. Practice guidelines for the management of bacterial meningitis. Clin Infect Dis. 39(9):1267-1284, 2004

17. Wyler A, Kelly W. Use of antibiotics with external ventriculostomies. J Neurosurg. 37(2):185-187, 1972

18. Zabramski JM1, Whiting D, Darouiche RO, Horner TG, Olson J, Robertson C et al. Efficacy of antimicrobial-impregnated external ventricular drain catheters: a prospective, randomized controlled trial. J Neurosurg. 98(4):725-730,2 003 